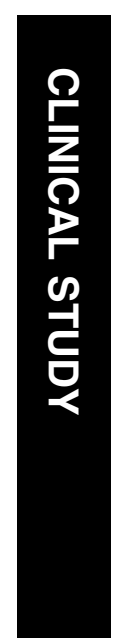

\title{
Anatomical and visual outcome of stages 4 and 5 retinopathy of prematurity
}

${ }^{1}$ Department of Pediatric Retina, Aravind Eye Hospital \& Postgraduate Institute of Ophthalmology, Coimbatore, Tamilnadu, India

${ }^{2}$ Childrens Retina Institute of California, Glendale, CA, USA

Correspondence: PK Shah, Department of Pediatric Retina,

Aravind Eye Hospital, Avinashi Road, Coimbatore-641 014, Tamil Nadu, India

Tel: + 91422 4360400; Fax: + 914222593030

E-mail: drshahpk@

vsnl.net

Received: 31 March 2007 Accepted in revised form: 6 July 2007

Published online: 3 August 2007

Financial interest: None

Presented in part at the Annual Meeting of the Vitreo Retinal Society of India, Ooty, February 24-27 2005

\begin{abstract}
Aim To describe our experience in surgical management of stages 4 and 5 retinopathy of prematurity (ROP) and assess its anatomical and visual outcome.

Materials and methods This study is a retrospective, interventional, consecutive case series. It involved 33 eyes of 29 infants. The data were retrieved retrospectively for each case from their medical records. All the eyes underwent primary vitrectomy with additional procedures like scleral buckling (two eyes), lensectomy (14 eyes), subretinal fluid drainage (two eyes), and one case of corneal transplant (open sky vitrectomy). The anatomical and visual outcome was reviewed at the final follow-up.
\end{abstract}

Results The mean gestational age was 29.7 weeks (range 25-34 weeks) and mean birth weight was $1332 \mathrm{~g}$ (range 650-2050 g).

Anatomical success for stage $4 \mathrm{~A}$ was defined as complete retinal attachment with undistorted or minimally distorted posterior pole. For stage $4 \mathrm{~B}$, partial residual retinal detachment and for stage 5 at least posterior pole attachment. Visual acuity was measured in anatomically successful eyes that were cooperative. The anatomical outcome was $90 \%$ (9/10 eyes) for stage $4 \mathrm{~A}, 44.4 \%$ (4/9 eyes) for stage $4 B$, and $14.3 \%(2 / 14)$ for stage 5 . The mean follow-up was $\mathbf{1 9 . 1}$ months. Posterior retinotomy was the commonest complication for stage $4 \mathrm{~B}(66.7 \%)$.

Conclusion Anatomical and visual success was the best for stage $4 \mathrm{~A}$ ROP. Surgery for stage $4 \mathrm{~A}$ can halt progression to stages $4 \mathrm{~B}$ or $5 \mathrm{ROP}$. Aggressive peeling of posterior membranes should be avoided for stage $4 \mathrm{~B}$. Anatomical and visual outcome is very poor for stage 5 .

Eye (2009) 23, 176-180; doi:10.1038/sj.eye.6702939; published online 3 August 2007
PK Shah ${ }^{1}$, V Narendran ${ }^{1}$, N Kalpana ${ }^{1}$ and

KA Tawansy²

Keywords: retinopathy of prematurity; surgery; stages 4 and 5; retinal detachment; vitreoretinal surgery

\section{Introduction}

Retinopathy of prematurity (ROP) is an avoidable cause of childhood blindness. Having screening protocols and meticulous examination by an experienced ophthalmologist is one of the main approaches to reduce the burden of this blindness. Awareness among pediatricians and ophthalmologists is a must to tackle this problem. Unfortunately, this is still lacking in countries like India especially in second and third tier cities.

The CRYO ROP study ${ }^{1}$ recommended that treatment at threshold stage can prevent progression to retinal detachment. Recently, the ETROP study ${ }^{2}$ has recommended earlier treatment of high-risk prethreshold stage. Inspite of cryo or laser at the given cutoff, quite a few eyes still proceed to stages 4 or 5 ROP. In developing countries, the situation is quite different. Still quite a few pediatricians refer to the ophthalmologist only when they or the parents notice leucokoria, when it is too late to do anything as far as giving normal vision is concerned. This is mainly due to lack of awareness.

Both scleral buckling ${ }^{3,4}$ and vitrectomy ${ }^{5,6}$ have been used to manage advanced ROP. In the past, scleral buckling was the treatment of choice and vitrectomy was considered only if buckle failed. But nowadays, primary vitrectomy is preferred. This study presents our experience in managing the stages 4 and 5 ROP.

\section{Materials and methods}

It is a retrospective study involving consecutive premature babies who were operated at our 
centre from July 2001 to November 2006. Thirty-three eyes of 29 babies underwent surgery. There were 12 females and 17 males. All the babies were examined preoperatively with indirect ophthalmoscopy and 28D lens. Alphonso speculum and a drop of $0.5 \%$ proparacaine hydrochloride were used for topical anaesthesia. B-scan was carried out where indicated. All the detachments were classified according to the international classification of ROP. ${ }^{7}$ Data on gender, gestational age, birth weight, post-natal age at surgery, and whether the eyes had received prior laser or cryo therapy were collected from the case sheets. Operative notes were reviewed to determine the surgical procedure performed on these eyes. Follow-up data were collected and the anatomical and visual function at last follow-up was noted. Pre- and postoperative Retcam pictures were taken whenever possible.

\section{Surgical procedure}

All the eyes in our series underwent vitrectomy. The choice of additional procedures was decided by the operating surgeon. Additional surgical procedures performed were scleral buckling, lensectomy, fluid air exchange, and injection of sodium hyaluronate (Healon, Advanced Medical Optics Inc., CA, USA).

\section{Stage 4}

The technique involved standard 20-guage three port pars plicata lens sparing vitrectomy (LSV). The sclerotomies are made $1 \mathrm{~mm}$ posterior to limbus through the pars plicata, as the pars plana is still not developed in these eyes. The lens in an infant occupies a lager portion of the posterior segment and therefore restrict intra-ocular manipulation and increase the risk of mechanical damage by the intra-ocular instruments. ${ }^{8}$ So, care should be taken not to injure the lens while introducing the instruments. The direction of entry should be more vertical towards the centre of the vitreous cavity. Initial core vitrectomy is carried out following which the traction forces between lens to ridge, ridge to ridge, ridge to periphery, and ridge to disc are addressed. In two cases where the ridge to periphery traction could not be relieved for fear of injury to the lens, a buckle was applied in the form of no. 41 silicon band.

\section{Stage 5}

In these cases, the ports are made $0.5 \mathrm{~mm}$ posterior to the limbus. The direction of entry is horizontal, directly in the anterior chamber. Lensectomy is performed first with the vitrectomy cutter. The posterior capsule is peeled next with an end-gripping forceps. In most cases, we cut the iris near the two superior ports along with the superior iris. The central membrane is then opened in a cruciate form with two 26-guage needles. Each arm of the triangular flap is then dissected till the periphery using forceps and blunt pick (bimanual technique). There are often multiple sheets of membranes, which have to be dissected layer by layer till one reaches the opening of the funnel. Healon is then injected in the funnel to open it followed by removal of posterior membranes and hyaloid remnants. In two eyes, subretinal fluid drainage was performed after filling the vitreous cavity with healon. In most cases, anterior peripheral dissection was very difficult and often left incomplete. Open-sky vitrectomy was carried out in one case who had formed a leucomatous opacity due to iris lens endothelium adhesions. Continuous infusion of chilled balanced salt solution was maintained through a bent cannula held by the assistant in this case. Healon was injected to maintain the globe once the funnel was opened.

Visual testing was limited to those babies who had anatomically attached retina and who were able to cooperate. Cycloplegic refraction was performed and correction given whenever possible. Visual acuity was recorded in Snellen equivalent if the child was cooperative. Visual function was recorded as hand movements by observation of the infants' ability to fix and follow, pick up small objects, and able to navigate. Perception of light (PL) present was defined as an avoidance response such as blink to bright light. It was recorded as PL absent if the child did not respond to bright light. ${ }^{9}$

\section{Results}

Thirty-three eyes of 29 babies were operated from July 2001 to November 2006. There were 12 females and 17 males. The mean gestational age was 29.7 weeks (range 25-34 weeks) and mean birth weight was $1332 \mathrm{~g}$ (range 650-2050 g). The breakup of gestational age and birth weight was as follows; three babies $(10.3 \%)$ had gestational age $<28$ weeks, $15(51.7 \%)$ had between 28 and 32 weeks, whereas $11(38 \%)$ had $>32$ weeks. Four babies $(13.8 \%)$ had birth weight $<1000 \mathrm{~g}, 18(62.1 \%)$ had between 1000 and $1500 \mathrm{~g}$, five (17.2\%) had between 1500 and $2000 \mathrm{~g}$, whereas two babies $(6.9 \%)$ had $>2000 \mathrm{~g}$. Ten eyes had stage $4 \mathrm{~A}$, nine had stage $4 \mathrm{~B}$, and 14 had stage 5 . There were total four babies who underwent surgery in both eyes. One child with bilateral stage 5 expired 1 month following his second eye surgery. Two babies with stage 5 did not give consent for surgery. They were excluded from the final analysis. Twenty-three eyes $(69.7 \%)$ had undergone prior laser or cryo for threshold ROP. The mean follow-up period was 19.1 months (range 1-57 months). Of the total 29 babies, 13 (44.9\%) were tertiary referral, whereas the remaining 16 (55.1\%) were screened by our hospital. 
Anatomical success for stage $4 \mathrm{~A}$ was defined as complete retinal attachment with undistorted or minimally distorted posterior pole. For stage $4 \mathrm{~B}$, partial residual retinal detachment and for stage 5 at least posterior pole attachment. Visual success was defined as central fixation for stage 4A, ambulatory vision for stage $4 \mathrm{~B}$ and form vision for stage 5 . LSV was carried out in all 10 eyes of stage $4 \mathrm{~A}$. Of the 10 eyes of stage $4 \mathrm{~A}$, six eyes were given prior laser, whereas four were late referrals (unlasered). Of these six eyes one had missed a follow-up post-laser and presented with other eye stage 5 ROP. The remaining five eyes progressed to stage $4 \mathrm{~A}$ inspite of adequate laser. The average number of laser spots in these six eyes was 2756 (range 600-5717). Of the four unlasered eyes, one child had bilateral stage $4 \mathrm{~A}$ with extensive fibrous proliferation over posterior pole. Both the eyes were operated on. This child was one of the twins, which had missed screening. The other twin had aggressive posterior ROP, which regressed post-laser. The remaining two babies, the other eye had progressed to stages $4 \mathrm{~B}$ and 5, respectively. All stage $4 \mathrm{~A}^{\prime} \mathrm{s}$, which present to our centre are not operated. Only those eyes, which are progressing inspite of good laser or unlasered late referrals, with activity are operated upon.

Eight eyes with stage 4B underwent LSV, whereas one eye had an additional lensectomy as the traction bands were extending till the lens. Additional scleral bucking was performed in two eyes. Of the 14 eyes with stage 5, all had lensectomy with vitrectomy, whereas one eye with adherent leukoma underwent additional corneal grafting (open-sky vitrectomy). Anatomical success was $90 \%(9 / 10)$ for stage $4 \mathrm{~A}, 44.4 \%$ (4/9) for stage $4 \mathrm{~B}$, and $14.3 \%(2 / 14)$ for stage 5 ROP. Overall anatomical success was $45.4 \%$ (15/33 eyes). Complete retinal attachment after stage 5 was seen in only one eye, which later redetached after 2 years. This eye had open-open configuration on ultrasound and had undergone prior laser treatment. Of the two eyes, which were anatomically successful, both had reattachment of posterior pole only. Visual outcome was available for eight out of nine eyes after successful surgery for stage $4 \mathrm{~A}$, three out of four successful eyes for stage $4 \mathrm{~B}$, and both the successful eyes of stage 5 . Five eyes had visual acuity of $6 / 24$ of which four were with stage $4 \mathrm{~A}$ and one with stage $4 \mathrm{~B}$. One eye of stage $4 \mathrm{~A}$ had visual acuity of $3 / 60$. Five eyes had hand movements of which three were of stage $4 \mathrm{~A}$ and two with stage $4 \mathrm{~B}$ and three eyes of stage 5 had PL present. Of the stage 5 eyes, six (43\%) had narrow-narrow configuration, seven (50\%) had opennarrow, and one $(7 \%)$ had open-open configuration. Anatomical success was seen in only two eyes (29\%) of seven, which had open-narrow configuration. All the rest failed to attach postoperatively. Additional membrane peeling was carried out during suture removal in the case of open-sky vitrectomy 10 weeks after initial surgery. None of the other cases underwent resurgery. Posterior retinotomy was the commonest intra-operative complication $(21.1 \%)$, followed by dialysis $(9.1 \%)$ and giant retinal tear (3\%). Three eyes developed cataract after LSV of which two were significant enough to undergo cataract extraction with intra-ocular lens implantation. All these eyes had some amount of vitreous traction extending till the lens. Of these nine were with stage $4 \mathrm{~A}$, seven with $4 \mathrm{~B}$ and 10 with stage 5 ROP.

\section{Discussion}

Laser photocoagulation is a very effective procedure for a majority of cases of high risk prethreshold or threshold ROP. Still a significant number of these eyes end in retinal detachment. In developed countries, most of these advanced ROP cases have had ablative treatment earlier. But in developing countries like India, one still sees quite a few cases of advanced ROP, which present late due to lack of screening.

Advances in vitreous surgery in infants and better understanding of its unique patho anatomy have changed the approach and prognosis especially for stage $4 \mathrm{~A}$ detachments. There is a trend now for earlier intervention in ROP-related detachments but proper timing is also critical especially if there is vascular activity. Gilbert et $a l^{10}$ noted that for stage $4 \mathrm{~A}$ ROP, the best chance of an interruption of progression to stage $4 \mathrm{~B}$ or 5 when the $4 \mathrm{~A}$ detachment does not progress beyond three segments. The timing of surgery for stage $4 \mathrm{~A}$ is an important consideration just as stage 3 requires rapid laser when threshold or high risk prethreshold is reached. The ideal timing for intervention is when the vascular activity is reduced and detachment is just begun. This usually occurs around the child's due date. The anatomical success of stage $4 \mathrm{~A}$ in our series was $90 \%$, which is comparable with that reported by Capone and Trese. ${ }^{11}$ Most of our cases underwent primary vitrectomy. Compared with scleral buckle, vitrectomy is more advantageous, as it directly addresses the trans vitreal traction. Moreover, scleral buckling requires additional procedure to divide at a later stage for the eye to keep growing. It also induces anisometropia of $-9.5 \mathrm{D}$ with residual myopia of $-5 \mathrm{D}$ even after the buckle is divided. ${ }^{12}$ Maguire and Trese ${ }^{13}$ have reported two port vitrectomy for these eyes using an infusion light pipe and vitreous cutter. However, we have used only the standard three port vitrectomy. Recently, 25-guage pars plicata vitrectomy has also been reported ${ }^{14}$ where the authors claim that the small instruments allows the surgeon easy access to anterior membranes in peripheral detachments in these small eyes. Visual outcome for 
stage $4 \mathrm{~A}$ was the best in our series, which is also proved in previous published studies. ${ }^{11,15}$ Fifty percent $(4 / 8)$ had final visual acuity of $6 / 24$. Surgery for stage $4 A$ has a better visual outcome, as it prevents detachment of the fovea, which has a devastating effect on visual acuity. We are also of the opinion that vitreous surgery can interrupt progression of ROP from stage $4 \mathrm{~A}$ to stages $4 \mathrm{~B}$ and 5 .

The anatomical and visual outcome for stage $4 \mathrm{~B}$ detachment was not as good as for stage $4 \mathrm{~A}$. The anatomical outcome was only $44.4 \%$. Posterior retinotomy was the commonest complication in these $4 \mathrm{~B}$ detachments $(66.7 \%)$. This may be due to aggressive peeling of the posterior membranes. The surgical goal for 4B detachments should be to minimize retinal distortion and prevent total detachment. Residual retinal detachment is common in these eyes and attempt should not be made to try to flatten the retina completely.

Anatomical outcome for stage 5 ROP was worst among all the detachments. As explained by Gopal et al, ${ }^{16}$ it is only the posterior vascularized retina, which gets detached and stretched all the way till the lens, whereas the redundant avascular retina remains attached. The anatomical success in our study is only $14.3 \%(2 / 14)$. Both the cases, which were successful, had only the posterior pole reattached. One case had complete reattachment till 2 years but later redetached. A comparision with previous studies is given in Table 1. Lakhanpal et $\mathrm{al}^{18}$ had divided the cases into two groups. Group 1 had undergone lensectomy with vitrectomy, whereas group 2 had additional $2 \mathrm{mg}(0.05 \mathrm{ml})$ injection of triamcinolone acetonate intravitreally at the end of surgery. Anatominal outcome was nil $(0 / 11)$ in group 1 , whereas it was $60 \%(6 / 10)$ in group 2 . They concluded that use of triamcinolone acetonate at the end of surgery may improve the likelihood of retinal reattachment in select cases of stage 5 . Visual outcome of stage 5 was also very poor in our series. Only three eyes (21.4\%) had PL present, whereas the rest had PL absent. Cusick et $a l^{9}$ reported 59\% with PL present, 26\% with PL absent, 10\% with hand movements, and $4 \%$ with more than $5 / 200$.

Table 1 A comparision of anatomical outcome of stage 5 ROP with previous studies

\begin{tabular}{lccc}
\hline Study & $\begin{array}{c}\text { No. of } \\
\text { eyes }\end{array}$ & $\begin{array}{c}\text { Anatomical } \\
\text { outcome (\%) }\end{array}$ & $\begin{array}{c}\text { Follow-up } \\
\text { (months) }\end{array}$ \\
\hline Lakhanpal ${\text { et } a l^{17}}^{17}$ & 33 & 45.5 & 48 \\
Lakhanpal al $^{18}$ & 21 & 28.6 & 28 \\
Cusick et al $^{9}$ & 608 & 28 & 44 \\
${\text { Gonzales } \text { et }^{14}}^{14}$ & 2 & 0 & 4.6 \\
${\text { Gopal } \text { et }^{16}}^{\text {Trese }}$ & 96 & 22.5 & 15.8 \\
Trese $^{20}$ & 45 & 45 & 6 \\
Present study $^{20}$ & 85 & 48 & 6 \\
\hline
\end{tabular}

Seaber et $a l^{21}$ reported $29.4 \%$ with PL absent, $21.6 \%$ with PL present, $39.2 \%$ with HM, and $9.9 \%$ with ambulatory vision. Seventy percent of our eyes has prior laser compared with only $10.4 \%$ reported by Gopal et al $^{16}$ and $22 \%$ by Cusick et al. ${ }^{9}$ Prior treatment was low in the study by Cusick as they had included cases from 1977 onwards. Surgical outcome was poorest in narrow-narrow configuration, which is comparable with previous studies.

The incidence of ROP especially zone 1 aggressive posterior ROP in bigger babies is on the rise in India. ${ }^{22}$ Usage of unmonitored oxygen is the most likely cause of this unusual ROP. Having regional guidelines to include these big babies for screening is not the only answer. The pediatricians and neonatologists have to be educated about the toxic effects of high oxygen on the developing retinal vasculature of newborn preterm infants, if the incidence of this dreadful disorder has to be reduced. There has been recent evidence that reduced oxygen can reduce the incidence of ROP even among the very small babies, which survive. ${ }^{23-25}$ We feel that the whole focus should be brought back to oxygen. Even in this study, there were two babies weighing more than $2000 \mathrm{~g}$ at birth similar to Gopal et $a l^{16}$ and 11 with gestational age more than 32 weeks.

Recently, intravitreal injection of antivascular endothelial growth factor has been given successfully in a case, which worsened in spite of prompt laser treatment and no negative effect on the growth of normal retinal vessels was noted. ${ }^{26}$ Pharmacotherapy may play an important role in the future. We hope that in the future, surgery can be avoided as far as possible in all cases of ROP, especially in bigger babies.

In conclusion, early LSV at stage $4 \mathrm{~A}$ can halt progression to stages $4 \mathrm{~B}$ and 5 ROP. Anatomical and visual outcome is poor for stages $4 \mathrm{~B}$ and especially for stage 5 ROP. These poor results reemphasize the need for increasing ROP awareness among the medical fraternity in India in order to reduce the incidence of this avoidable cause of childhood blindness.

\section{References}

1 Cryotherapy for Retinopathy of Prematurity Cooperative Group. Multicentre for trial for cryotherapy of retinopathy of prematurity: three month outcome. Arch Ophthalmol 1990; 108: 195-204.

2 Early Treatment of Retinopathy of Prematurity Cooperative Group. Revised indications for the treatment of retinopathy of prematurity. Arch Ophthalmol 2003; 121: 1684-1696.

3 Trese MT. Scleral buckling for retinopathy of prematurity. Ophthalmology 1994; 101: 23-26.

4 Greven C, Tasman W. Scleral buckling in stages $4 \mathrm{~B}$ and 5 retinopathy of prematurity. Ophthalmology 1990; 97: 817-820. 
5 Trese MT, Droste PJ. Long-term postoperative results of a consecutive series of stage 4 and 5 retinopathy of prematurity. Ophthalmology 1998; 105: 992-997.

6 Mintz-Hittner HA, O'Malley RE, Kretzer FL. Long-term form identification vision after early, closed, lensectomy-vitrectomy for stage 5 retinopathy of prematurity. Ophthalmology 1997; 104: 454-459.

7 International Committee for the Classification of the Late Stages of Retinopathy of Prematurity. An international classification of retinopathy of prematurity. Arch Ophthalmol 1987; 105: 906-912.

8 Greve MDJ. Vitreoretinal surgical anatomy. In: Peyman GA Meffert SA, Conway MD, Chou F (eds). Vitreoretinal Surgical Techniques. Martin Dunitz Ltd.:London, 2001, pp 3-9.

9 Cusick M, Charles MK, Agron E, Sangiovanni JP, Ferris FL, Charles S. Anatomical and visual results of vitreoretinal surgery for stage 5 retinopathy of prematurity. Retina 2006; 26: 729-735.

10 Gilbert WS, Quinn GE, Dobson V, Reynolds J, Hardy RJ, Palmer EA et al. Partial retinal detachment at 3 months after threshold retinopathy of prematurity. Long-term structural and functional outcome. Multicenter trial of cryotherapy for retinopathy of prematurity cooperative group. Arch Ophthalmol 1996; 114: 1085-1091.

11 Capone A, Trese MT. Lens sparing vitreous surgery for tractional stage $4 \mathrm{~A}$ retinopathy of prematurity detachments. Ophthalmology 2001; 108: 2068-2070.

12 Chow DR, Ferrone PJ, Trese MT. Refractive changes associated with scleral buckling and division in retinopathy of prematurity. Arch Ophthalmol 1998; 116: 1446-1448.

13 Maguire AM, Trese MT. Lens sparing vitreoretinal surgery in infants. Arch Ophthalmol 1992; 110: 284-286.

14 Gonzales CR, Boshra BS, Schwartz SD. 25-guage pars plicata vitrectomy for stage 4 and 5 retinopathy of prematurity. Retina 2006; 26: S42-S46.

15 Lakhanpal RR, Sun RL, Albini TA, Coffee R, Coats DK, Holz ER. Visual outcome after 3 port lens sparing vitrectomy in stage 4 retinopathy of prematurity. Arch Ophthalmol 2006; 124: 675-679.

16 Gopal L, Sharma T, Shanmugam M, Badrinath SS, Sharma A, Agraharam SG et al. Surgery for stage 5 retinopathy of prematurity: the learning curve and evolving technique. Ind J Ophthalmol 2000; 48: 101-106.

17 Lakhanpal RR, Sun RL, Albini TA, Holz ER. Anatomical success rate after primary three pot lens sparing vitrectomy in stage 5 retinopathy of prematurity. Retina 2006; 26: 724-728.

18 Lakhanpal RR, Fortun JA, Chan-Kai B, Holz ER. Lensectomy and vitrectomy with and without intravitreal triamcinolone acetonide for vascularly active stage 5 retinal detachments in retinopathy of prematurity. Retina 2006; 26: 736-740.

19 Trese MT. Surgical results of stage 5 retrolental fibroplasia and timing of surgical repair. Ophthalmology 1984; 91: 461-466.

20 Trese MT. Visual results and prognostic factors for vision following surgery for stage 5 retinopathy of prematurity. Ophthalmology 1986; 93: 574-579.

21 Seaber JH, Machemer R, Eliott D, Buckley EG, Dejuan E, Martin DF. Long term visual results of children after initially successful vitrectomy for stage 5 retinopathy of prematurity. Ophthalmology 1995; 102: 199-204.

22 Shah PK, Narendran V, Saravanan VR, Raghuram A, Chattopadhyay A, Kashyap M et al. Fulminate retinopathy of prematurity - clinical characteristics and laser outcome. Ind J Ophthalmol 2005; 53: 259-265.

23 Chow LC, Wright KW, Sola A. Can changes in clinical practice decrease the incidence of severe retinopathy of prematurity in very low birth weight infants? Pediatrics 2003; 111: 339-345.

24 Wright KW, Sami D, Thompson L, Ramanathan R, Joseph R, Farzavandi S. A physiologic reduced oxygen protocol decreases the incidence of threshold retinopathy of prematurity. Trans Am Ophthalmol Soc 2006; 104: 78-84.

25 VanderVeen DK, Mansfield TA, Eichenwald EC. Lower oxygen saturation alarm limits decrease the severity of retinopathy of prematurity. J AAPOS 2006; 10: $445-448$.

26 Shah PK, Narendran V, Tawansy KA, Raghuram A, Narendran K. Intravitreal bevacizumab (avastin) for anterior segment ischemia in agressive posterior retinopathy of prematurity. Ind J Ophthalmol 2007; 55: 75-76. 